\title{
A PANDEMIA DE COVID-19: REFLEXÕES À LUZ DO DIREITO AO DESENVOLVIMENTO, DIREITO À SAÚDE E DIREITO DO CONSUMIDOR
}

\author{
Ana Elizabeth Neirão Reymão* \\ Marcos Venancio Silva Assunção** \\ Roberta Pina Barbosa Faro ${ }^{* * *}$
}

\section{RESUMO}

Esse artigo busca refletir sobre a pandemia de COVID-19 e suas relações com o direito ao desenvolvimento, o direito à saúde e o direito do consumidor no Brasil. Indaga-se acerca dos desafios para a efetivação desses direitos no atual contexto. A pesquisa é exploratória e de abordagem qualitativa, trazendo o texto um breve panorama da pandemia e das crises dela decorrente. Discute o direito ao desenvolvimento, direito à saúde e direito do consumidor nesse contexto. Conclui-se pela importância da atuação estatal para mitigar os efeitos da crise e assegurar os direitos elencados.

Palavras-chave: Pandemia. COVID-19. Direito ao desenvolvimento. Direito à saúde. Direito do consumidor.

\section{THE COVID-19 PANDEMIC: REFLECTIONS IN THE LIGHT OF THE RIGHT TO DEVELOPMENT, RIGHT TO HEALTH AND CONSUMER RIGHT}

\begin{abstract}
This paper reflects on the pandemic of COVID-19 and its relations with the right to development, the right to health and the right of the consumer in Brazil. It is worried about the challenges for the realization of these rights in the current context. The research is exploratory and uses a qualitative approach, bringing the text a brief overview of the pandemic and the resulting crises. It discusses the right to development, the right to health and the right of the consumer in the context of it and concludes by the importance of State action to mitigate the effects of the crisis and ensure the rights listed.
\end{abstract}

Keywords: Pandemic. COVID-19. Right to development. Right to health. Consumer law.

\footnotetext{
* Economista (UFPA), Doutora em Ciências Sociais (UnB), Mestre em Economia (UNICAMP). Professora do Programa de Pós-Graduação em Direito, Políticas Públicas e Desenvolvimento (PPGD) do CESUPA. Professora da Faculdade de Economia da UFPA. Líder do grupo de pesquisas CNPq MinAmazônia (Mineração e Desenvolvimento Regional na Amazônia). E-mail: bethrey@uol.com.br

** Mestrando do Programa de Pós-Graduação em Direito, Políticas Públicas e Desenvolvimento do Centro Universitário do Pará (CESUPA). Bacharel em Direito e assessor de gabinete do $2^{\circ}$ Ofício Regional da DPU/PA. Integrante do grupo de pesquisas CNPq MinAmazônia (Mineração e Desenvolvimento Regional na Amazônia). E-mail: mvenan@gmail.com

*** Mestranda do Programa de Pós-Graduação em Direito, Políticas Públicas e Desenvolvimento do Centro Universitário do Pará (CESUPA). Bacharel em Direito e assessora da $2^{\text {a }}$ Vara de Execução Fiscal da Capital do tribunal de justiça do estado do Pará. Integrante do grupo de pesquisas CNPq MinAmazônia (Mineração e Desenvolvimento Regional na Amazônia). Bolsista CAPES. E-mail: robertapina@ @ hotmail.com
} 


\section{Introdução}

O objetivo desse artigo é trazer à reflexão alguns aspectos das relações entre a COVID-19, o direito à saúde e o direito do consumidor no Brasil, uma vez que se vivencia uma grave pandemia que traz uma crise humanitária e de saúde pública de grandes proporções, tendo como consequência um forte desequilíbrio social, econômico e ambiental que comprometem o direito ao desenvolvimento.

O desenvolvimento, como ensina Celso Furtado, pressupõe melhora da eficácia do sistema de produção, social, satisfação de necessidades básicas humanas (alimentação, habitação, saúde, educação, etc), devendo as mesmas serem compreensíveis a partir de um contexto cultural (FURTADO, 1964).

O direito ao desenvolvimento é um direito humano inalienável, que implica na necessidade de pessoas e povos terem acesso aos resultados dos ganhos das transformações econômicas, sociais, culturais e políticos, como prevê o artigo $1^{\circ}$ da Declaração sobre o Direito ao Desenvolvimento da Organização das Nações Unidas (ONU).

Na proteção a esse direito e tentativa de efetivá-lo, a Agenda 2030 proposta pela ONU definiu 17 Objetivos do Desenvolvimento Sustentável (ODS) para serem alcançados por seus países-membros, evidenciando a importância da atuação do Estado na promoção de políticas públicas.

Considerando o atual momento, em que a pandemia de COVID-19, decretada pela Organização Mundial da Saúde (OMS) em 11 de março de 2020, vem provocando uma crise sem precedentes, seja do ponto de vista comportamental, sanitário ou econômico, emerge, mais uma vez, a importância de discutir a saúde pública e, em particular, como se propõe esse texto, o direito à saúde.

O que se tem testemunhado, defende Davis (2020, p. 12), mostra que "a globalização capitalista parece agora biologicamente insustentável na ausência de uma verdadeira infraestrutura de saúde pública internacional". Apesar de riscos como os de epidemias anteriores, como a da SARS e do Ebola, terem emitido abundantes avisos e lições sobre o que seria necessário fazer, o sistema público de saúde dos países mostrou-se totalmente exposto e mal preparado para enfrentar uma crise como a trazida pela COVID-19, comprometendo o alcance do direito ao desenvolvimento.

Isso fere o expressamente apontado no ODS 3: “Garantir vidas saudáveis e bem-estar 
para todos em todas as idades". Em termos nacionais, conflita com o estabelecido no art. 196 da Constituição Federal de 1988 que, expressamente, tratar o direito à saúde como direito social fundamental. Cabe ao Estado garanti-la mediante políticas sociais e econômicas, de forma preventiva, sendo os serviços para sua promoção, proteção e recuperação de acesso universal e igualitário a todos.

Como direito fundamental, exige do Estado e da sociedade uma interpretação sistêmica dos demais direitos previstos na Carta Magna, tendo como base o princípio da dignidade do humano e do próprio direito à vida.

No atual momento de pandemia, outra questão importante e fortemente associada ao tema é quanto às muitas incertezas, tanto para o consumidor quanto para o fornecedor privado de saúde, acerca das relações de consumo no tema, uma vez que expressiva parcela dos brasileiros deles depende. Os contratos, os pactos que foram estabelecidos precisam observar o direito à saúde e ao desenvolvimento, impedindo que haja ampliação das desigualdades como consequência da crise trazida pela pandemia.

Nesse contexto, a reflexão proposta por esse artigo tem como problema de pesquisa, seguinte o questionamento: quais os desafios da pandemia de COVID-19 ao direito à saúde e o direito do consumidor no Brasil e seus impactos em termos de direito ao desenvolvimento?

Para discutir essa questão, metodologicamente, a pesquisa é, quanto aos objetivos, exploratória, e a abordagem qualitativa. Como procedimentos, adotou-se o levantamento bibliográfico e documental. Assim, o texto está estruturado em seis partes, incluindo essa introdução e as considerações finais. A seção 2 traz um breve panorama da pandemia de COVID-19 e a crise comportamental, sanitária e econômica dela decorrente. O direito ao desenvolvimento e o direito à saúde são discutidos nas duas seções seguintes. A seção 5 aborda o direito do consumidor, encerrando-se o texto com as conclusões do estudo.

\section{A pandemia de COVID-19 e a crise comportamental, sanitária e econômica}

Em 31 de dezembro de 2019, enquanto o mundo comemorava a chegada de uma nova década, o governo chinês comunicava à Organização Mundial da Saúde (OMS) um surto de doença respiratória aguda grave, com ocorrência na província de Hubei, com atualmente 58 milhões de habitantes, identificando maior incidência de contágio em sua capital, denominada Wuhan, cuja população é de 11,6 milhões de habitantes, com densidade 
demográfica de 9.600 pessoas por quilômetro quadrado. Até 12 de fevereiro, a China concentrava 99\% dos casos confirmados, mas já havia incidência de contaminação por COVID-19 em outros países o que levou a OMS a declarar, em 30 de janeiro de 2020, que se tratava de uma Emergência de Saúde Pública de Importância Internacional (OPAS, 2020), nos termos do Regulamento Sanitário Internacional.

Embora já houvesse um estudo publicado em 26 de janeiro de 2020, pelo Instituto de Sistemas Complexos da Nova Inglaterra, apontando um risco sistêmico de pandemia por um novo coronavírus e recomendando o uso do princípio da precaução e a redução drástica da mobilidade do vírus, a OMS só caracterizou a situação como pandemia em 11 de março de 2020, quando a doença já era uma realidade mundial (BAR-YAM, 2020). O coronavírus se espalhou vertiginosamente pela Ásia, Itália, Espanha, França, EUA e até então vem provocando uma crise sem precedentes no mundo.

No Brasil não foi diferente e, em 3 de fevereiro de 2020, o Ministério da Saúde declarou Emergência em Saúde Pública de Importância Nacional. Em 20 de março, com o Decreto Legislativo $\mathrm{n}^{\circ} 6$, foi reconhecida a ocorrência do estado de calamidade pública no país. Assim como nos demais países e atendendo as orientações da OMS, o país reconheceu que a pandemia de COVID-19 se tratava de uma Emergência de Saúde Pública de Importância Internacional. Ao final de março o país totalizava 201 mortes e 5.717 casos confirmados da doença.

Conti (2020) descreve a crise causada pela pandemia do vírus SARS-CoV-2 como "a crise tripla do COVID-19": crise comportamental, crise sanitária e crise econômica.

A crise comportamental está associada à ruptura e necessidade de rápida mudança de hábitos sociais. Nesse aspecto, hábitos da higiene como lavar as mãos e formas de cumprimento, uso de máscara, cortes de cabelo, barba, viagens e tantos outros serão alterados. Com a falta (ou redução) de reuniões presenciais, no trabalho as rotinas também se alteram: teletrabalho, telemedicina, mudanças nos padrões dos eventos, no tamanho dos encontros a serem realizados (festas, encontros sociais, congressos e reuniões científicas). Conti (2020, p. 6) lembra que também são necessárias mudanças no comportamento de governantes, de quem se requer "agilidade, transparência, comunicação verdadeira, decisões baseadas em evidências, corte de privilégios e de outros gastos supérfluos e redirecionamento de recursos".

A crise sanitária, por sua vez, relaciona-se fortemente à enorme probabilidade de colapso dos sistemas de saúde nos países, uma vez que a velocidade de propagação do vírus é 
muito grande e surpreendeu a todos, com perda de vidas e impactando as rotinas da maioria da população do mundo. Com a falta de médicos e outros profissionais e equipamentos de saúde, há um grande risco de colapso e aumento da letalidade não apenas da COVID-19, "mas também de todas as outras doenças e internações por conta da falta de leitos e profissionais de saúde", adverte Conti (2020, p. 6).

O sistema funerário, à exemplo do que se relatou em outras epidemias, como a da gripe espanhola no início do século XX, também pode colapsar, gerando cenas de terror, desespero e caos social. Vale lembrar que a gripe espanhola foi o nome que recebeu uma pandemia de vírus influenza que se espalhou pelo mundo entre 1918 e 1919, infectando cerca de 500 milhões de pessoas (próximo a 1/3 da população mundial na época), matando entre 25 milhões e 50 milhões, muitos com idade de 20 a 40 anos (1918 a 1920), como destaca Fioravanti (2020).

Se a atual pandemia não for reduzida rápida e substancialmente, as deficiências das estruturas sanitárias e de saúde reveladas durante o período pandêmico do início do século XX no Brasil poderão novamente ocorrer e gerar cenas como as abaixo relatadas:

A assistência pública não servia para nada, era apenas figurativa. Caso alguém passasse mal no meio da rua ficava dependendo ou da ajuda dos transeuntes, ou passava a vergonha de ser socorrido ou pelo camburão da brigada policial, ou pelo rabecão de alguma funerária.

A epidemia só fez explodir uma raiva acumulada durante anos contra as instituições de saúde e o desmazelo que o governo tinha para com a saúde de um modo geral. A espanhola veio, com certeza, tornar imperativo a melhoria da estrutura de saúde da cidade (GOULART, 2005, p. 106).

No trecho acima, referente ao que ocorreu no Rio de Janeiro, Goulart (2005) relata cenas muito tristes e expectativas negativas que estavam na rotina da cidade no começo do século, gerando distúrbios sociais e políticos como forma de reação da população ao quadro vivenciado.

Por fim, tem-se a crise econômica que, nas palavras de Conti (2020, p. 6), é representada pelas "dificuldades econômicas impostas pela mudança de comportamentos, aumento da aversão ao risco, medo crescente conforme o sistema de saúde colapsa, queda do comércio e investimentos internacionais". Por exemplo, no setor de aviação, com as viagens praticamente estagnadas, vive a ameaça de falência da maioria das empresas. Nos mercados de petróleo, a expectativa é de brusca queda no consumo global, fortemente afetado pela redução de voos, pelo fechamento de fábricas e outras medidas de contenção do novo coronavírus. O fechamento de bares, restaurantes, salões de beleza, o cancelamento de CONPEDI LAW REVIEW | EVENTO VIRTUAL | v. 6 | n. 1 | p. 53 - 74 | JAN - DEZ | 2020 
eventos culturais, entre tantos outros, certamente terá fortes impactos sobre a renda, o consumo, o emprego e vários indicadores econômicos e sociais.

Essa crise, em todas as suas dimensões, afeta a ação pública, conclamando a presença do Estado e sua atuação no sentido da proteção à vida e assegurar os direitos, que em suas múltiplas dimensões, envolvem a questão do direito ao desenvolvimento.

\section{O direito ao desenvolvimento e os ODS}

O desenvolvimento é um direito humano inalienável, devendo toda pessoa e todos os povos estarem habilitados a participar dos resultados dos avanços em termos econômicos, sociais, culturais e políticos, realizando plenamente todos os direitos humanos e liberdades. Essa é a previsão do artigo $1^{\circ}$ da Declaração sobre o Direito ao Desenvolvimento da Organização das Nações Unidas (ONU) (Resolução 41/128 da Assembleia Geral, de 4 de dezembro de 1986). Na Conferência Mundial sobre Direitos Humanos o desenvolvimento como direito foi reafirmado (artigo 10 da Declaração, de 12 de julho de 1993), colocando a pessoa humana como o sujeito central desse processo (PIOVESAN, 2010).

Destaca a autora que o direito ao desenvolvimento compreende três dimensões: participação, proteção às necessidades básicas de justiça social e adoção de políticas nacionais e de cooperação internacional.

A participação envolve transparência, democratização e accountability na gestão do orçamento público e na construção e implementação de políticas públicas. A proteção às necessidades básicas de justiça social implica em colocar o homem como o sujeito central do desenvolvimento e beneficiário do direito ao desenvolvimento. Por fim, a adoção de políticas nacionais e de cooperação internacional visa prover meios, especialmente para aos países em desenvolvimento, que encorajem esse direito (PIOVESAN, 2010).

Dessa forma, não há dúvidas de que esse direito pressupõe a atuação do Estado na promoção de políticas públicas com vistas à construção de uma ordem social que viabilize a autorrealização e a dignidade dos indivíduos e das coletividades. Nesse sentido, mais recentemente, a Agenda 2030 proposta pela ONU definiu 17 Objetivos do Desenvolvimento Sustentável (ODS), como desafio e requisito indispensável para efetivá-lo ${ }^{1}$.

\footnotetext{
${ }^{1}$ Os 17 Objetivos do Desenvolvimento Sustentável (ODS) são: 1. Acabar com a pobreza em todas as suas formas, em todos os lugares; 2 . Acabar com a fome, alcançar a segurança alimentar e melhoria da nutrição e CONPEDI LAW REVIEW | EVENTO VIRTUAL | v. 6 | n. 1 | p. 53 - 74 | JAN - DEZ | 2020
} 
Esses objetivos requerem uma abordagem multinível e multidisciplinar integrada para promover agendas de transformação relativas à erradicação da pobreza, segurança alimentar e agricultura, saúde, educação, igualdade de gênero, água e saneamento, energia, crescimento econômico sustentável, infraestrutura, redução das desigualdades, cidades sustentáveis, padrões sustentáveis de consumo e de produção, mudança do clima, proteção e uso sustentável dos oceanos e dos ecossistemas terrestres, sociedades pacíficas, justas e inclusivas e meios de implementação (PNUD, 2016). Ou seja, precisam se traduzir em políticas públicas na promoção do desenvolvimento sustentável.

A definição dos ODS evidencia uma tentativa de conexão entre os pilares econômicos, sociais e ambientais. O tema da saúde se é expressamente apontado no ODS 3 (Garantir vidas saudáveis e bem-estar para todos em todas as idades), e transversal a praticamente todos os demais, como no ODS 2 (Acabar com a fome, alcançar a segurança alimentar e melhorar a nutrição e promover a agricultura sustentável); no ODS 10 (Reduzir a desigualdade dentro e entre países); e no ODS 13 (Adotar medidas urgentes para combater as mudanças climática e seus impactos); entre outros.

No ODS 3, as metas previstas envolvem importantes temas: a redução da taxa de mortalidade materna global; acabar com as mortes evitáveis de recém-nascidos e crianças menores de 5 anos; a redução da mortalidade prematura por doenças não transmissíveis, reforçar a prevenção e o tratamento do abuso de substâncias, incluindo o abuso de drogas entorpecentes e uso nocivo do álcool; a redução das mortes e os ferimentos globais por acidentes em estradas, assegurar o acesso universal aos serviços de saúde sexual e reprodutiva; a redução do número de mortes e doenças por produtos químicos perigosos e por contaminação e poluição do ar, da água e do solo; e o fortalecimento a implementação da

promover a agricultura sustentável; 3. Assegurar uma vida saudável e promover o bem-estar para todos, em todas as idades; 4. Assegurar a educação inclusiva e equitativa e de qualidade, e promover oportunidades de aprendizagem ao longo da vida para todos; 5 . Alcançar a igualdade de gênero e empoderar todas as mulheres e meninas; 6. Assegurar a disponibilidade e gestão sustentável da água e saneamento para todos; 7. Assegurar o acesso confiável, sustentável, moderno e a preço acessível à energia para todos; 8 . Promover o crescimento econômico sustentado, inclusivo e sustentável, emprego pleno e produtivo e trabalho decente para todos; 9. Construir infraestruturas resilientes, promover a industrialização inclusiva e sustentável e fomentar a inovação; 10. Reduzir a desigualdade dentro dos países e entre eles; 11. Tornar as cidades e os assentamentos humanos inclusivos, seguros, resilientes e sustentáveis; 12. Assegurar padrões de produção e de consumo sustentáveis; 13. Tomar medidas urgentes para combater a mudança climática e seus impactos; 14 . Conservação e uso sustentável dos oceanos, dos mares e dos recursos marinhos para o desenvolvimento sustentável; 15. Proteger, recuperar e promover o uso sustentável dos ecossistemas terrestres, gerir de forma sustentável as florestas, combater a desertificação, deter e reverter a degradação da terra e deter a perda de biodiversidade; 16. Promover sociedades pacíficas e inclusivas para o desenvolvimento sustentável, proporcionar o acesso à justiça para todos e construir instituições eficazes, responsáveis e inclusivas em todos os níveis; 17. Fortalecer os meios de implementação e revitalizar a parceria global para o desenvolvimento sustentável.

CONPEDI LAW REVIEW | EVENTO VIRTUAL | v. 6 | n. 1 | p. 53 - 74 | JAN - DEZ | 2020 
Convenção-Quadro para o Controle do Tabaco da Organização Mundial de Saúde em todos os países (PNUD, 2016).

Sobre o combate a epidemias, está expressamente apontado em (3.3) “Até 2030, acabar com as epidemias de AIDS, tuberculose, malária e doenças tropicais negligenciadas, e combater a hepatite, doenças transmitidas pela água, e outras doenças transmissíveis”.

Na meta ODS (3.8), tem-se: “Atingir a cobertura universal de saúde, incluindo a proteção do risco financeiro, o acesso a serviços de saúde essenciais de qualidade e o acesso a medicamentos e vacinas essenciais seguros, eficazes, de qualidade e a preços acessíveis para todos".

Quanto a vacinas, medicamentos, financiamento da saúde e recrutamento, desenvolvimento, treinamento e retenção do pessoal de saúde, bem como o gerenciamento de riscos nacionais e globais à saúde, o ODS 3 define como metas:

3.b Apoiar a pesquisa e o desenvolvimento de vacinas e medicamentos para as doenças transmissíveis e não transmissíveis, que afetam principalmente os países em desenvolvimento, proporcionar o acesso a medicamentos e vacinas essenciais a preços acessíveis, de acordo com a Declaração de Doha sobre o Acordo TRIPS e Saúde Pública, que afirma o direito dos países em desenvolvimento de utilizarem plenamente as disposições do Acordo sobre os Aspectos dos Direitos de Propriedade Intelectual Relacionados ao Comércio (TRIPS, na sigla em inglês) sobre flexibilidades para proteger a saúde pública e, em particular, proporcionar o acesso a medicamentos para todos

3.c Aumentar substancialmente o financiamento da saúde e o recrutamento, desenvolvimento, treinamento e retenção do pessoal de saúde nos países em desenvolvimento, especialmente nos países de menor desenvolvimento relativo e nos pequenos Estados insulares em desenvolvimento

3.d reforçar a capacidade de todos os países, particularmente os países em desenvolvimento, para o alerta precoce, redução de riscos e gerenciamento de riscos nacionais e globais à saúde (PNUD, 2016, online).

Como se vê, a garantia de uma vida saudável pressupõe a ação pública em vários aspectos diretamente relacionados com a necessária atuação do Estado no contexto da pandemia de COVID-19: financiamento da saúde, pessoal de saúde, gerenciamento de riscos nacionais e globais à saúde, entre outros.

Alcançar essas metas é um grande desafio para as políticas públicas, uma vez que a proteção à saúde é uma das faces do direito ao desenvolvimento, o qual compreende múltiplas dimensões, implicando na adoção de medidas em âmbito nacional e de cooperação internacional. 
Esse desafio é maior ainda frente à pandemia do vírus SARS-CoV-2, a qual demanda não apenas medidas eficazes para seu enfrentamento, mas também uma reflexão sobre políticas públicas e direito à saúde, como se discute a seguir.

\section{Direito à saúde, judicialização da saúde e a pandemia de COVID-19}

A Constituição Federal foi expressa ao tratar o direito à saúde como direito social fundamental, estabelecendo o art. 196: 'A saúde é direito de todos e dever do Estado, garantido mediante políticas sociais e econômicas que visem à redução do risco de doença e de outros agravos e ao acesso universal e igualitário às ações e serviços para sua promoção, proteção e recuperação’ (BRASIL, 1988).

Exalce-se que ao elencá-lo na condição de direito fundamental, exige do Estado, e da sociedade como um todo, uma interpretação sistêmica dos demais direitos previstos na Carta Magna, integrando-o às perspectivas do princípio da dignidade do humano e do próprio direito à vida, exigindo uma tutela estatal preventiva.

Nesse contexto, inserem-se as políticas públicas, o "Estado em ação" (MULLER; SUREL, 2004). Demandam-se estratégias capazes de consolidar direitos assegurados primeiramente na Constituição do país e em outros dispositivos normativos que tratam do assunto, as políticas públicas na definição de Bucci (2001).

Secchi (2016) lembra que as políticas públicas tratam do conteúdo concreto e do conteúdo simbólico de decisões políticas, assim como de sua construção e atuação dos atores sobre as mesmas.

É nessa perspectiva que Lamarão Neto (2018, p. 89/90) destaca que o Estado tem relevante papel:

No campo dos direitos fundamentais, a saúde é uma tônica basilar do Estado Social de Direito, pois para além das meras prestações estatais devidas pela dicção normativa que lhe é inerente, posiciona-se como conditiosine qua non do exercício pleno das liberdades que permitem ao indivíduo executar seus planos racionais de uma vida boa na sociedade de cooperação, portanto, solidária, tendo-se sempre em mente que o Estado terá, nesse aspecto, por intermédio de suas políticas públicas, papel não apenas relevante, mas imprescindível e, portanto, determinante, para a consecução desses projetos.

A criação do Sistema Único de Saúde (SUS), em 1988, na Constituição da República Federativa do Brasil (CRFB), para articular ações e serviços de saúde a serem prestados em todos os níveis da federação, coordenando a atuação de diversos atores e estruturas envolvidas CONPEDI LAW REVIEW | EVENTO VIRTUAL | v. 6 | n. 1 | p. 53 - 74 | JAN - DEZ | 2020 
com as políticas sanitárias do Estado brasileiro é uma importante conquista social nesse sentido.

A saúde foi alçada à categoria de direito fundamental, sendo tarefa do Estado sua concretização e ampliação mediante a formulação, implementação, execução e fiscalização de políticas públicas. Tornou-se, então, direito dos cidadãos e dever do Estado, sendo o SUS o núcleo estruturante de todas as políticas sanitárias no país.

No contexto da pandemia de COVID-19, cumpre lembrar a importância do SUS e que sua organização se guia por diretrizes como a descentralização, o atendimento integral e a participação da comunidade. Com base nela são estruturadas ações e serviços de saúde, tanto promocionais, como de prevenção, cura e reabilitação pessoal, a serem prestados por órgãos e instituições públicas das três esferas governamentais, pela administração direta e indireta, bem como pelas fundações mantidas pelo Estado (OLIVEIRA, 2015).

Estima-se, segundo dados da Pesquisa Nacional de Saúde (2013), que 80\% da população depende do SUS para as ações relacionadas à assistência à saúde. E mais, mesmo quem possui plano privado de saúde usa o SUS direta ou indiretamente, por diversos serviços, desde alguns imunobiológicos e vacinas, até os mais caros, sendo quase todos os transplantes realizados apenas pelo SUS.

Além de estar presente no cotidiano do brasileiro nas ações de vigilâncias à saúde, como a epidemiológica, a sanitária e a ambiental. Ele está presente na água consumida, no ar, no solo das plantações, nos diversos medicamentos e produtos que demandamos, como o álcool em gel, que precisam estar de acordo com critérios de produção controlados pela Agência Nacional de Vigilância Sanitária (ANVISA).

Assim, adequada às perspectivas de um Estado Democrático de Direito, a Constituição Federal de 1988 buscou prever determinados tipos de direitos, como o à saúde, com o intuito de assegurar que sejam usufruídos e respeitados por todos, sem qualquer tipo de discriminação ou restrição, da mesma forma, que exigíveis a qualquer tempo.

Apesar de os direitos fundamentais não exigirem exemplificação por meio de rol rígido para que os seus titulares possam exercê-los, como destaca Piovesan (2010), estes encontram-se previstos nos ordenamentos de cada país, sendo limitados de acordo com as necessidades e as situações em que se inserem, muitas vezes, justamente, por meio de decisões fundamentadas em princípios. 
Um análise mais atenta, então, evidencia que os direitos fundamentais são espécie de nacionalização dos direitos humanos (inalienáveis, irrenunciáveis e imprescritíveis), fazendo com que cada Estado adote para si, e para seus cidadãos as ideias dissipadas mundialmente, especialmente por não abrangeram apenas um aspecto individual, mas também um sentido social, político, econômico, difuso e coletivo.

Em alguns casos, emerge um aparente conflito quando aplicados ao caso concreto, de modo que, ainda sob o ideal da democracia, faz-se necessário atender aos interesses não apenas de um indivíduo, mas tentar adequá-los ao interesse de uma sociedade inteira, na condição de direitos abstratos que não tem hierarquia entre si, resultando, na necessidade de apreciação judicial.

O reconhecimento da pandemia pela Organização Mundial da Saúde (OMS) traz, inclusive, uma nova perspectiva à própria soberania dos países, inclusive no tocante às relações internacionais direcionadas ao controle de seus próprios interesses, considerando que vários Estados-nações optaram pelo fechamento de suas fronteiras, impedindo a entrada de estrangeiros vindos de fora do país, conforme ocorrido no Brasil, com a edição da Portaria $n^{\circ}$ 8, de 2 de abril de 2020, como medida necessária para conter os avanços da propagação do vírus em território nacional, resguardando o direito à saúde de seus cidadãos e mesmo de estrangeiros, que aqui já se encontravam.

Assim, consagrado no art. $6^{\circ}$ da Constituição Federal, enquanto direito social a ser assegurado pelo Estado a todos os cidadãos, o direito à saúde exige uma postura ativa do Estado, muitas vezes, por meio de condutas que poderão vir a ensejar alterações orçamentárias, demandando uma atuação que possibilite a promoção, proteção e recuperação da saúde, como trata o trecho a seguir:

Tem-se que a saúde, enquanto decorrência do princípio fundamental da pessoa humana, é um direito subjetivo, o que significa dizer que "ao titular de um direito fundamental é aberta a possibilidade de impor judicialmente seus interesses juridicamente tutelados perante o destinatário (obrigado)" e, portanto, quando há decisão judicial "compelindo a Administração Pública a fornecer gratuitamente um medicamento, cumpre o comando constitucional que assegura o direito à saúde e, portanto, o efetiva" (ROCHA, 2019, p. 50).

Neste contexto, a judicialização da saúde tem espaço importante no debate sobre o ativismo judicial brasileiro uma vez que, ao lado da importância da atuação ativa do Estado na garantia do direito à saúde, por meio do SUS, observa-se a crescente judicialização das relações sociais, políticas e econômicas. Esse ativismo tem se tornado uma prática jurídica 
contemporânea, na qual os juízes, dispondo de discricionariedade judicial, tem decidido, inclusive, muitas vezes, fora dos limites exatos do direito, como conclui Verbicaro (2017).

O tem vem ganhando cada vez mais destaque nacional e, por isso, desde 2009, as decisões judiciais têm analisado as demandas de saúde de maneira mais científica, principalmente a partir da instalação do Fórum Nacional do Poder Judiciário para a Saúde e, posteriormente, com os CIRADS (LAMARÃO NETO, 2018).

Por certo, não se olvida a celeuma inicial acerca da possibilidade ou não de o Poder Judiciário vir a decidir sobre tal matéria, repercutindo na judicialização da saúde e no proferimento indiscriminado de decisões nesta seara, além da discussão atinente à separação de poderes.

Sabe-se, no entanto, que a judicialização de demandas direcionadas à área da saúde partiram sobremaneira da má atuação da Administração Pública no tocante ao atendimento de cidadãos, que muitas vezes tinham seu acesso ao Sistema Único de Saúde (SUS) limitado, especialmente no que diz respeito às pessoas hipossuficientes economicamente, que necessitadas de tratamento médico adequado passaram a demandar do Poder Judiciário uma atuação positiva, por meio da prolação de decisão judicial, que assegure o efetivo gozo de um direito constitucionalmente previsto, a fim de evitar que tragédia maior aconteça.

Esse quadro preocupa especialmente quando se observa que o cenário vivenciado em meio a pandemia, não apenas em âmbito nacional, repercutiu de forma crítica nos sistemas de saúde, os quais, assoberbados frente à urgência e aumento não esperado do número de pacientes, demandando leitos e outros tipos de cuidados médicos, resultaram em hospitais abarrotados em um curto espaço de tempo, ensejando a criação de diversos hospitais de campanha, destinados ao atendimento exclusivo de paciente com sintomas da COVID-19.

A gravidade da situação fez, inclusive, com que estádios de futebol, por exemplo, tivessem seu uso destinado à realização de tratamentos de pacientes diagnosticados.

Também com vistas a garantir a existência de leitos, a Agência Nacional de Saúde Suplementar (ANS), órgão regulador vinculado ao Ministério da Saúde no Brasil, responsável pelo controle dos planos de saúde, orientou que consultas, exames ou cirurgias que não se enquadrem em casos de urgência e emergência fossem adiadas, no intuito de conter a aceleração do contágio.

Nesta ótica, nota-se ainda mais, a necessidade de cautela e maior precisão técnica por parte do juiz. Isto porque, ao adentrar em tal discussão, necessariamente o julgador passará 
por aspectos financeiros e orçamentários inerente aos comandos do poder executivo, que, imersos numa "cegueira em relação aos encantos da Justiça Constitucional", podem vir a usurpar competências que sequer lhes competem (VERBICARO, 2017), especialmente em um período onde o uso dos recursos públicos foi liberado em favor dos governos locais, para utilização discricionária em vistas a adoção de ações de combate, ocasião em que, aquando da apreciação do pleito antecipatório da medida cautelar na Ação Cível Originária $n^{\circ} 3.375$, ajuizada pelo estado do Espírito Santo, o Ministro Relator Alexandre de Moraes pontuou:

O direito à vida e à saúde aparecem como consequência imediata da consagração da dignidade da pessoa humana como fundamento da República Federativa do Brasil. Nesse sentido, a Constituição Federal consagrou, nos artigos 196 e 197, a saúde como direito de todos e dever do Estado, garantindo sua universalidade e igualdade no acesso às ações e serviços de saúde.

A gravidade da emergência causada pela pandemia de COVID-19 (Coronavírus) exige das autoridades brasileiras, em todos os níveis de governo, a efetivação concreta da proteção à saúde pública, com a adoção de todas as medidas possíveis para o apoio e manutenção das atividades do Sistema Único de Saúde.

Cabível pontuar, que não são poucos os poderes atribuídos ao juiz para a entrega da prestação jurisdicional (art. 297 do CPC), havendo de atentar-se, no entanto, que a todo poder corresponde uma responsabilidade, de modo que, certamente, o julgador deve ter o controle da situação, devendo necessariamente considerar que no outro polo da demanda existe(m) outro(s) sujeito(s) de direitos que serão atingidos pela decisão judicial, tendo a obrigatoriedade de motivar seu convencimento de modo claro e preciso (art. 298, CPC).

Nesta ótica, a discricionariedade inerente à atuação dos juízes deve ser observada com prudência e maior rigor, considerando a estruturação do sistema inerente à nossa sociedade e, especialmente, frente a progressividade da judicialização de demandas desta natureza, exigindo uma postura ativa, tendo em que, inobstante advenham de decisões proferidas em processos individualizados, projeta consequências coletivas, ensejando a necessidade de observância de limites interpretativos, a fim de evitar o arbítrio judicial e o subjetivismo aquando da apreciação do feito, com o fito de evitar uma atuação prejudicial aos interesses coletivos, ante a visão estrita que é apresentada ao julgador aquando da análise do caso concreto (LAMARÃO NETO, 2018). 
A necessidade de padronização da atuação judicial no tocante a observância de parâmetros e contornos mínimos de exigências para o deferimento do pleito, sob o risco de resultar na transferência maciça dos problemas sociais, políticos e econômicos nas mãos de um poder que não fora eleito para tanto, especialmente, que, sequer eleito pelo povo (VERBICARO, 2017).

Não fosse apenas isto, a própria Constituição traz limitação à tal atuação, ao elencar princípios outros que também exigem seu cumprimento, tal como a necessidade de atenção ao princípio da reserva do possível, o qual, sempre conjugado à perspectiva do mínimo existencial, resulta na identificação e necessidade de conformação de determinadas políticas públicas aos limites financeiros destinados pelo poder público àquele setor, tal como ocorre no tocante aos hospitais; unidades de pronto atendimento; fornecimento de medicamentos; contratação de profissionais da área médica etc.

Muito associado a essas questões, outro aspecto jurídico relativo às crises causadas pela pandemia causada pelo vírus SARS-CoV-2 envolve as relações de consumo, como trata a próxima seção.

\section{O direito do consumidor na pandemia de COVID-19}

Após ser declarada como pandemia global pela Organização Mundial da Saúde (OMS), a COVID-19 tem impactado praticamente todos países, alcançando também o Brasil e vários setores da economia mundial. A crise é sistêmica e afeta fortemente as relações de consumo, demandando que consumidores e fornecedores negociem. É um momento de muitas perdas, especialmente para os que estão em posição de vulnerabilidade, que perdem muito mais. Assim como nas demais áreas, o setor de saúde também vem sendo bastante atingido, sofrendo inúmeras mudanças, em meio a muitas dúvidas e incertezas, que exigem medidas rápidas e eficazes para amenizar os impactos negativos da crise para ambos os lados.

Cumpre, assim, nessa parte do artigo, fazer algumas reflexões sobre a importância do direito do consumidor na garantia do direito à saúde, como via de acesso ao desenvolvimento, impedindo que haja ampliação das desigualdades como consequência da crise trazida pela pandemia. 
Como já mencionado, a Constituição Federal brasileira, em seu art. 196, e a Lei 8.080/90, garante que todo brasileiro tenha direito à saúde pública, sendo o Sistema Único de Saúde (SUS) um meio para efetivá-la. O país adota o sistema universal em que "a saúde é direito de todos e dever do Estado". O sistema oferece assistência médica, vigilância sanitária, financia pesquisas em saúde e fornece medicamentos gratuitos. Além disso, usuários de planos de saúde privados também podem utilizar o sistema de saúde pública. Em contrapartida, as operadoras dos planos privados deve reembolsar os cofres públicos, sempre que um de seus beneficiários usar o SUS para um serviço que esteja previsto no contrato do plano, conforme a Lei 9.656/98.

Um relatório publicado pelo Banco Mundial em 2017 demonstra que mais da metade dos gastos totais com saúde no Brasil são financiados privadamente (individualmente e por planos de saúde privados):

Nas duas últimas décadas, o gasto com saúde como parte do PIB aumentou em 1,8 pontos percentuais no Brasil, enquanto que, entre os países da OCDE, o aumento da média foi de 2,3\%. Diferentemente da maioria dos seus parceiros econômicos, mais da metade dos gastos totais com saúde no Brasil são financiados privadamente (individualmente e planos de saúde privados) (THE WORLD BANK, 2017, p.110).

Em 2018, em pesquisa realizada pelo SPC Brasil e Confederação Nacional dos Dirigentes Lojistas do Brasil (CNDL), constatou que 30,3\% têm plano de saúde, pago pela empresa do beneficiário $(13,2 \%)$ ou pago integralmente pelo próprio beneficiário $(11,5 \%)$; outros $69,7 \%$ dos entrevistados não têm plano de Saúde médico particular e, quando necessitam do serviço, utilizam o SUS $(44,8 \%)$ ou pagam do bolso $(24,9 \%)$ (SPC BRASIL, 2018). Os dados demonstram que uma parcela expressiva da população, cerca de 47 milhões de pessoas, utiliza planos de saúde, ou pagam com dinheiro do próprio bolso, suas despesas com saúde.

Justamente no ano em que o Código de Defesa do Consumidor (CDC), completa 30 anos, seu regramento terá que enfrentar talvez o seu maior desafio, desde sua vigência, em promover a justiça e garantir a possibilidade de desenvolvimento dos sujeitos envolvidos nas relações de consumo, afetadas não pela ação das partes, mas por fato superveniente, de força maior, a saber o confinamento da população, sobretudo no que diz respeito às questões de saúde.

Em todo país, a medida em que o confinamento se prolonga e a crise financeira se agrava, problemas com a utilização dos planos de saúde vão surgindo, sendo de extrema 
importância o olhar do direito sobre os contratos firmados. Muitos beneficiários ficarão inadimplentes por perda de emprego, benefícios e redução de salários, e isso incidirá em juros de mora e suspensão dos atendimentos. Nesse sentido, a Agência Nacional de Saúde Suplementar (ANS) definiu novas medidas para mitigar os impactos da pandemia de coronavírus no setor de planos de saúde e propôs que, a partir da data da assinatura do contrato, até o dia 30 de junho de 2020, as operadoras de plano de saúde garantam o atendimento aos inadimplentes, mesmo que passados os 60 dias previstos em lei (ANS, 2020).

Nos casos de em que os contratos estabelecem critérios para os sinistros, e as operadoras venham a repassar seus custos operacionais, nos próximos reajustes, sob a justificativa de que a pandemia obrigou a preparação de vagas em stand by para UTIs, elevou os custos de insumos importados, a exemplo do que ocorreu com álcool em gel e máscaras de proteção, deve-se ter em conta que a sinistralidade não é aceita sem qualquer limitação, nem mesmo em contextos de normalidade, quando o pacta sunt servanda funciona como a regra.

Por esse tipo de mecanismo, as operadoras de planos de saúde transferem os riscos de sua atividade, aumentando o valor das contraprestações mensais, ganhando assim, vantagem excessiva sobre os beneficiários. Esse procedimento viola o Código de Defesa do Consumidor nos artigos 39, inciso $\mathrm{V}$, que veda ao fornecedor de produtos ou serviços, dentre outras práticas abusivas: exigir do consumidor vantagem manifestamente excessiva, bem como o art. 51, XIII, que define como nulas de pleno direito, as cláusulas contratuais relativas ao fornecimento de produtos e serviços, que autorizem o fornecedor modificar unilateralmente o conteúdo, ou a qualidade do contrato, após sua celebração (SILVA, 2020).

Ressalte-se ainda, a relevância do art. 14, da Lei 8.078/90 (CDC), que estabelece a teoria do risco do negócio, como fundamento as relações de consumo, que atribui responsabilidade civil objetiva para os fornecedores, independente de culpa, considerando apenas a apresentação do nexo causal entre o defeito do produto ou serviço e o acidente de consumo. Por esse entendimento, cabe ao fornecedor os assumir os riscos em potencial de seus produtos ou serviços, bem como a prevenção de possíveis danos que prejudiquem o consumidor, do contrário, terão indenizar os prejuízos causados por sua atividade econômica.

Assim, diferentemente do Código Civil de 2002, o CDC não levou em conta o caso fortuito e a força maior como causas excludentes de responsabilidade, posto que a responsabilidade em regra é objetiva, admitindo-se o instituto da excludente apenas em caso 
de ilegitimidade do fornecedor ou em caso fortuito externo, quando o risco da relação não decorre da ação direta do fornecedor.

Sabe-se que no direito privado a força maior é uma exceção, e isso também se aplica nas relações de consumo. Para Antonio H. Benjamim, a excludente de força maior deve ser aplicada ao direito do consumidor, já que se trata de fato externo, superveniente, cujos efeitos são imprevisíveis, eliminando o nexo causal entre o fato danoso e a relação de consumo nele mesmo (BENJAMIM, 2018). É o caso da atual pandemia e a decretação do estado de calamidade pública.

As normas do Código de Defesa do Consumidor são protetivas e partem do princípio de que o consumidor final é a parte mais fraca da relação contratual, portanto é vulnerável. Prevendo em seu art $4^{\circ}$ que:

\begin{abstract}
A Política Nacional das Relações de Consumo tem por objetivo o atendimento das necessidades dos consumidores, o respeito à sua dignidade, saúde e segurança, a proteção de seus interesses econômicos, a melhoria da sua qualidade de vida, bem como a transparência e harmonia das relações de consumo (BRASIL, 1990, online).
\end{abstract}

Desse modo, a interpretação das cláusulas contratuais nas relações de consumo exige que se olhe de de forma favorável para o consumidor, obrigando a nulidade imediata de qualquer pacto contratual abusivo, que o coloquem em posição de desvantagem. Isso é tão importante que o artigo $6^{\circ}$, inciso $\mathrm{V}$, do $\mathrm{CDC}$, prevê que as cláusulas contratuais, excessivamente onerosas ao consumidor em razão de fatos supervenientes, poderão ser revistas. Por essa perspectiva, a crise atual não altera o sentido da norma, permanecendo as garantias legais de proteção ao consumidor. Este, salvo melhor entendimento, estaria livre do pagamento de multas contratuais, já que tem o direito de pedir remarcações e reembolsos e proteções.

Ao mesmo tempo, não se pode desconsiderar o fato de que as operadoras, pela mesma lei, não podem responder por inadimplementos decorrentes de força maior, pois esta exclui reciprocamente as responsabilidades. Assim, o microssistema que está estruturado para a defesa do consumidor, entende que é necessário preservar o equilíbrio das relações nesse momento, sob pena de onerar de forma excessiva ao fornecedor ou prestador de serviços, que desempenha também uma função social importante na cadeia produtiva, tendo que responder por todos os ônus decorrentes de um fato inesperado, vindo de fora da relação de consumo, e que não decorreu do exercício de atividade econômica (MARQUES et al, 2020). 
Nesse contexto parece inevitável a judicialização das relações de consumos nas questões de saúde. Sendo assim, espera-se que os magistrados considerem ao julgar tais demandas, os impactos sociais reais consequentes de suas decisões, tendo em mente que o ativismo judicial:

não é o fenômeno isolado de alguns juízes que anseiam brigar com o poder público, haja vista que muitas vezes o magistrado é socialmente impelido a se pronunciar sobre a interpretação de uma legislação inacabada ou a julgar algum conflito que deveria ter sido resolvido na esfera do debate político, funcionando como a última voz com autoridade para tal. (VERBICARO; VERBICARO; MACHADO, 2018, p. 197).

Em última análise, a crise trazida pelo coronavírus, interfere diretamente nas relações cotidianas da sociedade, causando prejuízos tanto para o consumidor final, quanto para prestadores de serviços e fornecedores, sem que ambas as partes tenham dado causa, exigindo que que se atente ao bom senso e aos princípios fundamentais previstos na Constituição, sobretudo o da isonomia (art. $5^{\circ}$ caput), a fim de se tratar igualmente os iguais e desigualmente os desiguais na exata medida de suas desigualdades.

Nessa perspectiva, torna-se importante refletir sobre o direito do consumidor em associação com o direito à saúde, devendo a questão estar de acordo com os requisitos necessários para assegurar o desenvolvimento no país. No entanto, não resta dúvida que um importante aprendizado mundial e nacional dessa pandemia é de que o fortalecimento de sistema de saúde público e cada vez mais inclusivo é a melhor forma para garantir a saúde como direito fundamental.

\section{Considerações finais}

O artigo buscou analisar algumas relações entre a COVID-19, o direito à saúde e o direito do consumidor no Brasil, trazendo grandes desafios à concretização do direito ao desenvolvimento.

A grave pandemia, provocada por um novo coronavírus, o SARS-COV-2, tem causado uma crise humanitária e de saúde pública de abrangentes proporções. Ao se espalhar pelo mundo, atingindo indivíduos vulneráveis e impactando fortemente comportamentos, tem ameaçado os sistemas de saúde e as economias e mostrando estreita relação com o direito ao desenvolvimento. A enorme probabilidade de colapso nos sistemas de saúde, devido ao 
grande contingente de pacientes que buscam as unidades de saúde de uma só vez, coloca em risco a vida de muitas pessoas.

Em um curto espaço de tempo, então, governos de diversos países passaram a se debruçar sobre questões ligadas diretamente ao gozo de direitos individuais e coletivos, como direito à saúde e o direito do consumidor, as quais, em verdade, há tempos já demandam uma atuação estatal e, recentemente, ganharam holofotes considerando os números de infectados e de óbitos declarados em razão da pandemia.

A desigualdade econômica e social tem afetado consideravelmente a população mais vulnerável no Brasil no exercício de direitos ligados ao desenvolvimento, como saúde, educação e assistência social, inobstante as políticas públicas deverem estar associadas à necessidade precípua de reduzi-la. Em tempos de pandemia, devem focar principalmente nos mais vulneráveis.

Assim, se, por um lado, são as normas substanciais, isto é, civis, administrativas, consumeristas etc., em conjunto com os direitos, implícita e explicitamente assegurados na Constituição Federal, os responsáveis por assegurar ao cidadão o gozo dos benefícios que lhes são garantidos em um Estado Democrático de Direito, faz-se necessária a atuação estatal com a elaboração de políticas públicas, oportunizando o gozo de direitos, especialmente do direito à saúde, inerente à própria condição humana.

A pandemia tem mostrado que um grande desafio no Direito Sanitário global é a harmonização de temas e a coordenação dos interesses dos atores nos processos políticos de negociação de normas internacionais de interesse à saúde. No cenário impulsionado pela globalização, os Estados e o setor da saúde precisam recuperar seu objetivo final: a proteção da saúde.

Como adverte Bihr (2002, p. 25): “A situação criada pela pandemia de COVID-19 é uma demonstração real e irrefutável da falência da tese defendida durante décadas pelos defensores da abertura do sistema de saúde".

No Brasil, a criação do SUS representou a estruturação de um sistema de distribuição de saúde como um importante passo na realização de uma justiça social, notadamente por ser ele universal, integral e solidário. Como em outras epidemias, como na gripe espanhola, a falta de leitos suficientes, a importância da notificação precisa e a garantia do acolhimento para todos somente pode ser enfrentada por um sistema com a capilaridade do SUS. Infelizmente ele não tem recebido os investimentos necessários nos últimos anos, mas não 
resta dúvida que ele possui tecnologia e histórico de enfrentamento de doenças e epidemias. Assim, entende-se que é importante sua revitalização e estruturação como suporte central para quaisquer medidas de controle da atual e de outras pandemias.

Adicionalmente, o enfrentamento da atual crise não olvida a importância de também disciplinar esferas das relações de consumo, regulamentando-as por meio do direito do consumidor. Muitos brasileiros dependem de planos privados de saúde, sendo mais da metade dos gastos totais com saúde no país a eles ligados. Para esses casos e à luz do CDC é imprescindível que as negociações se estabeleçam considerando o princípio da boa-fé objetiva, a base norteadora das relações de consumo. Por esse princípio se espera uma postura leal, fundada na confiança despertada na outra parte contratante, respeitando suas expectativas legítimas e contribuindo para a segurança das relações negociais.

Deve o Estado buscar um equilíbrio jurídico entre as partes, impedindo-as de dispor de forma contrária às normas estabelecidas, como forma de política pública necessária à preservação de direitos individuais e coletivos e assegurar a proteção do consumidor final.

A atual pandemia representa um grande desafio para o CDC na promoção da justiça no que diz respeito às relações de consumo nas questões de saúde. Como mostrado, a ANS tem definido novas medidas para mitigar os impactos da pandemia, propondo que as operadoras de planos de saúde garantam o atendimento aos inadimplentes, ainda que passado o prazo previsto em lei. Obrigou, ainda, a preparação de vagas nas UTIs, considerando a atual pandemia e a decretação do estado de calamidade pública.

Entende-se o quadro vivenciado demanda um conjunto de políticas públicas para assegurar à pessoa o bem-estar físico e mental, conferindo-lhe a desafiadora tarefa de assegurar o direito ao desenvolvimento, na condição de direito fundamental, sem macular sobremaneira aspectos do direito do consumidor e o resguardo à vida.

\section{Referências}

BENJAMIN, Antonio Herman. Transporte aéreo e o Código de Defesa do Consumidor. Revista de Direito do Consumidor, 2018.

BRASIL. Lei $\mathrm{n}^{\circ}$ 8.078, de 11 de setembro de 1990. Código de Defesa do Consumidor. Brasília, DF. Disponível em: http://www.planalto.gov.br/ccivil_03/leis/18078.htm. Acesso em 3 Abr. 2020. 
BUCCI, Maria Paula Dallari. Buscando um conceito de políticas públicas para a concretização de direitos humanos. In: Direitos humanos e políticas públicas. Cadernos Pólis 2. São Paulo: Pólis, 2001, p. 5-16.

CONFEDERAÇÃO NACIONAL DOS DIRIGENTES LOJISTAS DO BRASIL (CNDL). SPC Brasil. Gastos dos brasileiros com saúde. Pesquisa. Janeiro 2018. Disponível em: https://www.spcbrasil.org.br/wpimprensa/wp-content/uploads/2018/02/An\%C3\%A1liseGastos-com-Sa\%C3\%BAde.pdf. Acesso em: 17 abr. 2020.

CONTI, Thomas V.. Crise Tripla do Covid-19: um olhar econômico sobre as políticas públicas de combate à pandemia. Working Paper. 2020. Disponível em: http://thomasvconti.com.br/pubs/coronavirus/. Acesso em: 12 Abr. 2020.

BIHR, Alain. França: pela socialização do aparato de saúde. In: DAVIS, Mike, et al: Coronavírus e a luta de classes. Terra sem Amos: Brasil, 2020, p. 25-30.

DAVIS, Mike. A crise do coronavírus é um monstro alimentado pelo capitalismo. In: DAVIS, Mike, et al. Coronavírus e a luta de classes. Terra sem Amos: Brasil, 2020.

FURTADO, Celso. Dialética do desenvolvimento. Rio de Janeiro: Fondo de Cultura, 1964.

FIORAVANTI, Carlos. Semelhanças entre a gripe espanhola e a Covid-19. 26 mar. 2020. Disponível em: https://revistapesquisa.fapesp.br/2020/03/26/semelhancas-entre-a-gripeespanhola-e-a-covid-19/. Acesso em Acesso em: 12 Abr. 2020.

GOULART, Adriana da Costa. Revisitando a espanhola: a gripe pandêmica de 1918 no Rio de Janeiro. Hist. cienc. saude-Manguinhos, Rio de Janeiro , v. 12, n. 1, p. 101-142, Apr. 2005. Disponível em: http://www.scielo.br/scielo.php?script=sci_arttext\&pid=S010459702005000100006\&lng=en\&nrm=iso. Acesso em: 15 Apr. 2020.

INSTITUTO BRASILEIRO DE GEOGRAFIA E ESTATÍSTICA. Pesquisa Nacional de Saúde 2013. . Rio de Janeiro: IBGE, 2013. Disponível em: http://www.ibge.gov.br/home/estatistica/populacao/pns/2013/. Acesso em 29 Mar. 2020.

LAMARÃO NETO, Homero. Judicialização da saúde: o indivíduo e a sociedade de cooperação. Rio de Janeiro: Lumen Juris, 2018.

MARQUES, Claudia Lima. BERTONCELLO, Karen. LIMA, Clarissa C. Exceção dilatória para os consumidores frente à força maior da pandemia de covid-19. Pela urgente aprovação do PL 3.515/2015 de atualização do CDC e por uma moratória aos consumidores. Revista de Direito do Consumidor 129 (2020), p. 14ss.

MULLER, Pierre.; SUREL, Yves. A análise das políticas públicas. Pelotas: Educat, 2004, p. 11 .

OLIVEIRA, Heletícia Leão de. Direito fundamental à saúde, ativismo judicial e os impactos no orçamento público. Curitiba: Juruá, 2015.

OPAS BRASIL (ORGANIZAÇÃO PAN-AMERICANA DA SAÚDE - OPAS). OMS declara emergência de saúde pública de importância internacional por surto de novo 
coronavírus. 30 de janeiro de 2020. Disponível em: https://www.paho.org/bra/index.php?option=com_content\&view=article\&id=6100:omsdeclara-emergencia-de-saude-publica-de-importancia-internacional-em-relacao-a-novocoronavirus\&Itemid=812. Acesso em: 10 abr. 2020.

PIOVESAN, Flávia. Direito ao desenvolvimento: desafios contemporâneos. Direito ao Desenvolvimento. Belo Horizonte: Fórum, p. 95-116, 2010.

PROGRAMA DAS NAÇÕES UNIDAS PARA O DESENVOLVIMENTO (PNUD). As perguntas mais frequentes sobre os Objetivos de Desenvolvimento Sustentável (ODS), 29 jun. 2016. Disponível em: https://www.undp.org/content/dam/brazil/docs/ODS/undp-br-odsFAQ.pdf. Acesso em: 15 mai.2019.

ROCHA, Glenyo Cristiano. Judicialização da política e efetivação de direitos fundamentais: sob a perspectiva da tutela de saúde. Rio de Janeiro: Lumen Juris, 2019.

SECCHI, Leonardo. Políticas públicas: conceitos, esquemas de análise, casos práticos. São Paulo: Cengage Learnig, 2016.

SILVA, Julio César Ballerini. Coronavírus e contratos de plano de saúde. Revista Jus Navigandi, ISSN 1518-4862, Teresina, ano 25, n. 6117, 31 mar. 2020. Disponível em: https://jus.com.br/artigos/80635. Acesso em: 18 abr. 2020.

THE WORLD BANK. A Fair Adjustment: Efficiency and Equity of Public Spending in Brazil. Size I: Overview. Nov 2017. Disponível em https://www.worldbank.org/en/country/brazil/publication/brazil-expenditure-review-report. Acesso em: 15 abr. 2020.

VERBICARO, Dennis; VERBICARO, Loiane Prado; MACHADO, Ana Victória Delmiro. A Sociedade Juridificada e o Desmoronamento Simbólico do Homem Democrático: Relações entre Judiciário, Mídia e Opinião Pública. Revista Juridica, [S.1.], v. 53, n. 4, p. 190 - 212, fev. 2020. ISSN 2316-753X. Disponível em: http://revista.unicuritiba.edu.br/index.php/RevJur/article/view/3215. Acesso em: 18 abr. 2020.

VERBICARO, Loiane Prado. Judicialização da política, ativismo e discricionariedade judicial. Rio de Janeiro: Lumen Juris, 2017. 